Svetlana Verytelnyk, Ph.D. student of Donetsk State University of Management (Mariupol, Ukraine)

\title{
THE FORMATION OF FUTURE SUSTAINABLE DEVELOPMENT OF UKRAINE: ISSUES AND CURRENT STATE
}

Abstract. Ensuring sustainable (balanced) development is a complex task that requires a systematic approach. One of the important aspects of this security system is management. In this context, it is difficult to overestimate the role of public administration - from the formation of its principles, goals and objectives to making specific decisions on their implementation. Public administration is defined as a deliberate influence on social processes, encompassing the actions of governmental and non-governmental actors such as civil society, scientists, researchers and private organizations. Not only international or national, but also regional and local levels of governance, ensuring their systematic activity, which determines the success or failure of joint efforts, is critical for the sustainable (balanced) development implementation, since in the context of globalization, harmonized public governance at all territorial levels is a necessary condition for achieving the goals and objectives of sustainable development.

Global issues require not only timely response but concerted precautionary action at all levels. It is in this chain that it is often revealed that management experts have been called "evolutionary dichronosis" which is the lag of public administration systems adaptation from the pace of change occurring at different levels of government requiring new approaches, ideas and new management decisions. This is why special attention is paid to management issues in the formulation of proposals for Sustainable Development Goals (SDGs) for the period after 2015, taking into account the three main aspects of governance - good governance, effective management and fair management.

Institutional capacity of authorities at different levels to make responsible decisions, formulate realistic goals, apply adequate indicators that demonstrate their achievement, implement sustainable management models that are acceptable for the effective implementation of sustainable development policies, and create conditions for such development - all these components of public administration are considered in the suggested guide. Particular attention is paid to the issues of decision-making in public administration in the development and implementation of sustainable (balanced) development policies. 
Keywords: sustainable development, public administration, international cooperation, international agreements and conventions

\section{Introduction}

Currently, the preconditions for Ukraine's transition to a model of sustainable (balanced) development are unfavourable. Due to many factors, the potential of economic, environmental and social resources for sustainable (balanced) development of the country has undergone significant destructive changes. As a result, these are the low positions that Ukraine occupies in terms of the overall development equation among other countries of the world, the issues of economic and social development of the country, the unfavourable ecological situation in Ukraine. However, despite all the complexity of the situation, it has considerable potential of resources, mobilization of which can provide an improved situation and become the basis for gradual transition of the country to the model of sustainable (balanced) development.

\section{International agreements Ukraine has acceded}

Ukraine signs the documents of the United Nations Conference on Environment and Development (Rio de Janeiro, 1992) and the World Summit on Sustainable (Balanced) Development (Johannesburg, 2002), the documents of the United Nations Conference on Balanced Development (Rio de Janeiro, 2012). Ukraine approved the Program of Action for the Further Implementation of the Agenda for the 21st Century, adopted at the Nineteenth Special Session of the UN General Assembly (1997) and the UN Millennium Declaration (Millennium Development Goals), adopted by the UN General Assembly (2000). This is a testament to the fact that Ukraine accepts the concept of sustainable (balanced) development as the basic paradigm of human development in the 21 st century and confirms its adherence to the principles of sustainable (balanced) development.

Unfortunately, the period that Ukraine experienced after the Rio Conference (1992) coincided with the difficult years of the new state institutions and socio-political relations formation, with a profound transformation of Ukraine's economy and a total economic crisis. This made it necessary to focus the activities of the state and society on the state formation issues, the national security system formation, the nuclear weapons elimination, the aftermath of the Chernobyl nuclear power plant disaster mitigation, and the systemic reforms implementation. The situation is especially aggravated by the annexation of Russia to Crimea and the armed conflict in eastern Ukraine. 
Adoption and practical implementation of sustainable (balanced) development principles took place in Ukraine through a number of laws and state programs of various levels preparation, which legally and practically identified the priorities of Ukraine and its regions' development with emphasis on ceasing environmental degradation, using balanced natural resources and promoting nature conservation [1]. The basic principles of the sustainable (balanced) development concept were elaborated by scientific institutes, state institutions and public organizations. Ukraine has acceded to a number of international agreements and other instruments directly or indirectly related to solving the issue of humanity's transition to sustainable (balanced) development.

Ukraine is actively involved in international cooperation on sustainable (balanced) development, environmental protection, and counteraction to global climate change. The country is a member of the UN Human Rights Council, the Economic and Social Council, participates in the activities of the United Nations Economic Commission for Europe to strengthen regional cooperation in the fields of energy, transport, and environment and cooperates with the UN Forest Forum and the Sustainable Development Commission UN [2].

The paradigm of sustainable (balanced) development was implemented in Ukraine both through the implementation of the provisions of the Agenda for the 21st Century and the decisions of the World Summit on Sustainable (Balanced) Development, and by joining new and implementing international agreements on this issue in the national regulatory framework.

Ukraine is a partner to more than 40 global and regional conventions and agreements on sustainable (balanced) development, although they are predominantly environmental. Thus, for the period 2002-2012, Ukraine acceded to a number of international treaties, namely:

- Convention on Cooperation for the Protection and Sustainable Use of the Danube River (Convention for the Protection of the Danube River) (ratified by Law No. 2997-III of 17.01.2002);

- Cartagena Protocol on Bio-safety to the Convention on Biological Diversity (Law of Ukraine No. 152-IV of 12.09.2002);

- Rotterdam Convention on the Prior Informed Consent Procedure for Certain Hazardous Chemicals and Pesticides in International Trade (Law No. 169-IV of 26.09.2002);

- the Nagoya Protocol on the Regulation of Access to Genetic Resources and Sharing on a Fair and Equal Ground to Benefit from their Application to the Convention on Biological Diversity (signed by Ukraine on 29.10.2010); 
- Framework Convention for the Protection and Sustainable Development of the Carpathians (the Convention was ratified by Law No. 1672-IV of April 7, 2004);

- Protocol on conservation and sustainable use of biological and landscape diversity to the Framework Convention on the Protection and Sustainable Development of the Carpathians, signed in Kyiv on May 22, 2003 (Protocol ratified by Law No. 1621-VI of 04.09.2009);

- Protocol on Sustainable Forest Management to the Framework Convention for the Protection and Sustainable Development of the Carpathians (Protocol ratified by Law No. 5432-VI of 16.10.2012);

- European Landscape Convention (Convention ratified by Law No. 2831-IV of 7 September 2005);

- Stockholm Convention on Persistent Organic Pollutants (ratified by Law No. 949$-\mathrm{V}$ of 18.04.2007);

- Agreement on the Conservation of the Cetaceans of the Black Sea, the Mediterranean Sea and the adjacent Atlantic Ocean (accession in accordance with Law No. 1067-IV of 09.07.2003);

- Agreement on the Conservation of Afro-Eurasian Migratory Wading Birds (Agreement ratified by Law No. 62-IV of 04.07.2002) [2].

The abovementioned points out that Ukraine is cooperating with other members of the world community in terms of the sustainable (balanced) development principles implementation. To a large extent, due to the commitments made in the international agreements signed by Ukraine, certain practical steps have been taken in our country to implement the sustainable (balanced) development principles.

However, these steps are rather exceptions than regularities. In general, the state of affairs regarding the implementation of the basic development paradigm set out in the Agenda for the 21 st Century in Ukraine leaves much to be desired. Until now, in Ukraine, there has been no practical harmonization at the state level of the proper integration of economic, environmental and social policies reflected in the relevant legal documents.

In the years after Rio, appropriate concepts or strategies for sustainable (balanced) development have been developed at the regional and city levels. Similarly, concepts or strategies have been developed for the sustainable (balanced) development of particular sectors of the economy or types of economic activity. However, they were created as separate documents, not as links of one system of measures at the local, regional and national levels to regulate economic, social, environmental and other aspects of development. 
On June 27, 2014, Ukraine signed and on September 16 ratified the Association Agreement between Ukraine and the EU. Among other things, the Agreement sets out the task of further implementation of the sustainable (balanced) development principles in Ukraine and the normative provisions of the EU legislation in this field. First of all, it concerns the environmental and ecological aspects of sustainable (balanced) development. In particular, the Agreement contains provisions on cooperation in the field of environmental protection (Chapter 6).

Thus, Article 360 states: "The Parties shall develop and strengthen environmental cooperation and thereby contribute to the achievement of the long-term objectives of sustainable development and the green economy. Enhanced environmental protection is expected to have positive consequences for citizens and businesses in Ukraine and the EU, in particular through improvements to the health care system, conservation of natural resources, increased economic and environmental performance, integration of environmental policy into other country's policy areas, as well as production level due to modern technologies. Cooperation shall be based on the interests of the Parties on the basis of equality and mutual benefit, as well as taking into account the interdependence between the Parties in the field of environmental protection and multilateral agreements in this field" [3].

Article 361 states the objective of cooperation in the field of conservation: "Cooperation shall aim at preserving, protecting, improving and restoring the quality of the environment, protecting public health, prudent and rational use of natural resources and promoting measures at the international level aimed at addressing community and regional decisions, global environmental problems, inter alia, in the following areas:

a) climate change;

b) environmental management and related issues, including education and training, access to environmental information and decision-making;

c) ambient air quality;

d) water quality and management of water resources, including the marine environment;

e) waste and resource management;

f) conservation of nature, in particular the conservation and protection of biological and landscape diversity (ecosystems);

g) industrial pollution and industrial threats;

h) chemicals;

i) genetically modified organisms, including in agriculture; 
j) noise pollution;

k) civil protection, in particular natural disasters and anthropogenic threats;

1) urban environment;

m) environmental changes" [3].

The Agreement also contains an obligation of the country to adapt the legislation of Ukraine to the EU legislation on the environment. According to Article 363: "The gradual approximation of Ukraine's legislation to EU environmental law and policy shall be in accordance with Annex XX to this Agreement" [3]. In total, Ukraine has to implement $26 \mathrm{EU}$ Directives and 3 EU Regulations into national law. This has to be completed in a timely manner. It cannot be but mentioned that there exist traditional trends in Ukraine's failure to comply with international commitments in time.

Since the Rio de Janeiro Conference in 1992, the institutional framework for sustainable (balanced) development has expanded significantly. There are now more than 500 multilateral environmental agreements in place, which have expanded the scope of public administration to sustainable (balanced) development. At the same time, the degradation of the natural resource base is continuing, the climate is changing and the poverty rate remains high. These processes question the capacity of the existing institutional framework to contribute to the stated goals.

A significant obstacle to achieving sustainable (balanced) development in Ukraine, as in the whole world, is the lack of a coherent approach that would fully integrate the three components of sustainable (balanced) development. On the contrary, the number of different processes focused on each component has increased. Therefore, there is a need for a holistic approach to sustainable (balanced) development that will integrate economic, social and environmental approaches.

The integration of the three main components of sustainable (balanced) development can be achieved primarily through strategic planning at the global and national levels. The main task at the global level is to define the international community of international goals for sustainable (balanced) development, at the national level - to define the national goals of sustainable (balanced) development in national forums and to adopt them in appropriate national strategies. In this way, each country can choose its own model of sustainable (balanced) development [1]. 


\section{Concept, Strategy and National Action Plan for the Transition to Sustainable} (Balanced) Development

In the Program of Action for the Further Implementation of the Agenda for the 21st Century, adopted at the nineteenth special session of the UN General Assembly (1997), all the countries that approved it, including Ukraine, committed themselves to developing by 2002 National Sustainable (Balanced) Development Strategies.

The National Strategy for Sustainable (Balanced) Development is a key element in the system of legislative instruments that have to determine the path to sustainable (balanced) development of each country. The basis for the strategy development is the appropriate concept of transition to sustainable (balanced) development, and the strategy as a political document underlies the national action plan as a more specific document, which outlines specific tasks, executors, financial resources and their sources, etc. for the purpose and goals motions for sustainable (balanced) development, formulated in a concept and specified in a strategy.

The example of such harmonization of normative acts in the legislation of Ukraine is the Law of Ukraine "On the basics (strategies) of the state environmental policy of Ukraine for the period up to 2020" (2010) and "National Environmental Action Plan of Ukraine for the period from 2011 to 2015 " (2011).

Many attempts have been made in Ukraine to develop and approve the Concept of Sustainable (Balanced) Development of the Country. In particular, it is the Draft Concept prepared in accordance with the decree of the Presidium of the NAS of Ukraine No. 355 of 02.06.2006 by the Institute of Nature Management and Ecology and the Institute of Market and Economic and Ecological Research of the NAS of Ukraine. Specialists of the Institutes of Geography, Ecology of the Carpathians, and the Council for the Study of Productive Forces of Ukraine of the NAS of Ukraine participated in the elaboration of this draft Concept.

This draft Concept was considered and approved at a meeting of the working group chaired by Academician of the NAS of Ukraine led by V. Kuhar on October 18, 2006. Later it was considered and affirmed under the UNESCO program "Man and Biosphere" on November 16. However, it was not possible to approve the Concept at the state level. The next attempt was made only 6 years later.

In February 2012, at the initiative of representatives of three institutes of NAS of Ukraine - Institute of Geography (Kyiv), Institute of Market Problems and Economic-Environmental Researches of NAS Ukraine (Odessa). 
The Institute for Environmental Management and Ecology (Dnipro) has made another effort to ensure that the Concept of Sustainable Development is adopted at the Rio+ 20 Summit in Ukraine. With the participation of representatives of these institutes, representatives of other academic scientific institutions, high schools of science, members of public environmental organizations, in particular the All-Ukrainian Ecological League, a new version of the concept was prepared, incorporating all the developments made in the previous versions of the concepts, adapted accordingly to the new conditions, to the current requirements. The draft concept was discussed and approved at the International Environment Forum "Environment for Ukraine" (April 24-26, 2012), during its elaboration the propositions and comments received from some interested bodies of the central executive power and experts were taken into account.

The project identified, in particular, the main objectives (Scheme 1), the achievement of which is necessary for the country's transition to sustainable (balanced) development.

The goals of proposed Concept of sustainable (balanced) development of Ukraine:

Goal 1. The decrease of environmental degradation and transition to balanced natural resource management.

Goal 2. The formation of new economy model based on the durable and regenerated natural resource management.

Goal 3. The improvement of people well-being.

Goal 4. The formation of general awareness, Ukrainian outlook in terms of sustainable development ideas.

Goal 5. The formation of legal and regulatory and institutional basis for sustainable development provision.

Goal 6. Keeping national principles and traditions concerning natural resource management.

Goal 7. The protection of nation interests of Ukraine in the scope of globalization process.

Goal 8. Ensuring all interested stakeholders participation in sustainable (balanced) development policy formation and implementation.

Goal 9. The formation and implementation of regional policy concerning sustainable (balanced) development. 


\section{Scheme 1}

The accompanying letter of the President of the NAS of Ukraine B. Paton No. 9p / 619-1 dated 2 April 2012 sent the revised concept to the Cabinet of Ministers of Ukraine. The draft concept was approved by the Verkhovna Rada Committee on Environmental Policy, Environmental Management and Consequences of the Chornobyl Catastrophe, the Ministry of Ecology and Natural Resources of Ukraine, the Ministry of Youth and Sports of Ukraine, the Ministry of Economic Development and Trade of Ukraine, the Ministry of State Affairs of Ukraine Department of Geology and Subsoil of Ukraine, State Agency of Water Resources of Ukraine. Unfortunately, this Concept has not yet been formally recognized by the State (Scheme 1).

On January 12, 2015, the President of Ukraine, by Decree No. 5/2015, approved a document entitled "Ukraine 2020 Sustainable Development Strategy". However, this document needs considerable refinement in order to find the principles and approaches that define the essence of the basic paradigm of the 21 st century.

The Strategy for Sustainable (Balanced) Development of Ukraine has to become a program document that combines on a systematic basis the economic, environmental, social and cultural aspects of the country development for the long term. Specific measures for the strategy implementation have to be developed and approved in the relevant National Action Plan.

This strategy and measures for its implementation in Ukraine have to be considered as an integral part of the overall strategy of humanity's transition to sustainable (balanced) development.

In particular, it is necessary to ensure that the basic principles of the strategy for sustainable (balanced) development of Ukraine are aligned with the relevant principles enshrined in the Rio de Janeiro, Johannesburg documents, the principles of ensuring the sustainable (balanced) development of the European continent, developed and approved by the Council of Europe. The main goals of sustainable (balanced) development, formulated in these documents, are to ensure its socio-natural efficiency, namely: economic growth, improving the living conditions of present and future generations, ensuring the balance of energy needs of society with energy resources of nature and preserving its socio-economic functions. The idea is to preserve the biosphere as a living environment for future generations through the balance of socio-economic and environmental development and the renaturalization of nature. 
The main goals of the Sustainable (Balanced) Development Strategy of Ukraine are logically derived from the goals and objectives set forth in the Agenda 21 and the principles of sustainable (balanced) development contained in the Declaration on Environment and Development adopted at the Rio-92 Conference. In particular, the principle \# 3, according to which "the right to development should be implemented in such a way as to ensure that the needs of the present and future generations in the fields of development and the environment are justly met" [4].

At the same time, the strategic goals of Ukraine's transition to sustainable (balanced) development is to ensure high standards of citizens quality of life for long-term; to create opportunities to meet the material and spiritual needs of present and future generations of Ukrainian citizens; to ensure their long-lasting, healthy and sufficient life in a favorable for living environment, respecting the proper level of environmental safety in the country as a state of protection of the vital interests of the individual, with successes, states, biota from the adverse effects of the environment caused by natural (biotic and abiotic) and anthropogenic factors.

This requires the achievement of an adequate level of competitiveness of the state and its integration into the world community on the basis of ensuring national interests in economic, social, environmental, spiritual and other spheres, full realization of the integral potential of the country's development.

Creating opportunities for the practical transition of Ukraine to sustainable (balanced) development requires awareness from all segments of society as for the need to make such a transition as a virtually non-alternative condition for securing the country's future, preserving its environment and favourable conditions for long-term development of the society. This awareness is especially essential at the level of decision-makers and executors.

The implementation of the principles of sustainable (balanced) development requires: significant transformations of worldview, political, economic, technical and technological, communication and information, social spheres; the speedy accumulation of national capital; increase of intellectual and information potential; renaturalization of nature; preservation of national wealth, spiritual culture, strengthening of moral foundations and ensuring adaptation of the population to new conditions of business and life in general. The stated goals have to be realized in the transition of Ukraine to sustainable (balanced) development.

Optimizing the relationship between society and nature in the territory of Ukraine requires consolidation of Ukrainian society, awareness of citizens and country authorities of 
their unity, a clear definition of national strategic interests of the country and citizens and the implementation of policies to ensure their practical implementation.

\section{Mechanisms, milestones and expected results of program measures implementation in transition to sustainable (balanced) development}

The issue of mechanisms for implementing the strategy of sustainable (balanced) development of Ukraine deserves special attention. It has to be considered based primarily on the peculiarities of the country situation as part of the world community. The lack of consideration and neglect of the factor of development processes dependence at the level of Ukraine in all their aspects from the development of the same processes at the global level reduces the degree of their realization probability.

Among the regularities of Ukraine's movement towards a model of sustainable (balanced) development, the following has to be mentioned:

1. The conditionality of mechanisms for implementing the model of sustainable (balanced) development in the post-crisis state of the Ukrainian economy and the need for large-scale structural and technological transformations of production in order to provide further country transition to post-industrial development.

2. Different ways of restructuring the social-natural energy balance from the developed countries of the world. Thus, economic growth provided the expansion of ecological space for people and nature conservation requires not substantial reduction, but substantial expansion of production in Ukraine based on the introduction of energy-saving technologies, development of tertiary and quaternary sectors of the economy, science-intensive industries.

3. The need for expanded reproduction of all components of national capital human, financial, natural, material, etc., requiring state support for domestic production, improving the well-being of the population through the implementation of effective financial and credit and fiscal regulatory tax policy.

4. The need to stop the depopulation process and significantly improve the health and environmental situation in order to improve the gene pool of the population and ensure its widespread reproduction.

5. Compliance of the location of environmental infrastructure objects to the production territorial structure.

6. Transition to the policy of renaturalization of nature instead of its protection. 
The realization of the strategic goals and conceptual principles embodied in the Rio idea requires a thorough scientific substantiation of the tactics and mechanisms for their implementation. Under the mechanisms of ensuring sustainable (balanced) development, the author understands the system of methods, forms, tools and levers to ensure sustainable (balanced) social, economic, environmental and spiritual development of the country.

As abovementioned, the Concept of Sustainable (Balanced) Development in Ukraine is based on the idea of socio-economic and ecological balance for guaranteeing favourable living conditions of modern and future generations and aimed at securing Ukraine's national interests in the complex processes of its entry into the world community. Therefore, the implementation of a sustainable (balanced) development model in Ukraine requires the involvement of a complex poly-structured system of legal, economic and other mechanisms. In the most general form, the following types can be defined:

I. State-regulatory mechanisms that integrate a system of actions and measures aimed at harmonizing social-natural relations to ensure the sustainable (balanced) development of Ukraine; this system has to be implemented in all directions of public policy: tax, budgetary, financial, credit, legal, investment, industrial, social, foreign economic, environmental, etc.

II. Legal mechanisms embodied in the legislative support of transformation and adaptation processes of country economic growth on the basis of market economy.

III. Financial mechanisms of state regulation aimed at:

a) balance of intergovernmental (vertical and horizontal) and intra-budgetary (income-expenditure) relations;

b) the focus of budget provision on the support of the domestic producer, the implementation of strategically important domestic social and economic programs;

c) strengthening the fiscal and regulatory functions of the tax service of Ukraine in order to increase the population economic activity;

d) orientation of financial and credit policy on support and activation of business performance, agrarian sector, ensuring the balance of credit demand and credit supply in the country;

e) increase of investment attractiveness.

IV. Economic and production mechanisms that combine different methods, forms, measures to increase the economic potential of the state, strengthen social productivity and development of an innovative complex, ensure the domestic 
products and services competitiveness, structural and technological restructuring of the economy on the basis of technical and technological reconstruction, ensure the modern energy and resource-saving technologies, low-waste technologies implementation, guarantee production, information-communication, market infrastructure development, etc.

V. Socio-economic mechanisms aimed at: a) increasing the employment of the population, primarily through job creation, in particular in rural areas; b) reducing the socio-financial stratification of society by establishing the middle class and significantly increasing its income share; c) ensuring compliance with the remuneration volumes of its effectiveness; d) effective protection of the population's income from inflation; e) the creation of an effective social security system that would ensure every employee's contribution to all types of insurance payments, including pensions; e) financial support for real, targeted social protection of vulnerable population groups.

VI. Social outlook, scientific and educational mechanisms of transition to sustainable (balanced) development, which would provide: a) restructuring of ideology of social-natural relations on the basis of their parity recognition; b) development of basic and applied research on problems of socially, economically and environmentally-balanced development; c) training of relevant specialists in all fields of knowledge in compliance with modern mentality and provided with the latest knowledge on the science and technology achievements; d) civil solution of coexistence issues of all denominations in Ukraine, etc.

VIII. Ecological mechanisms that provide for the greening of production with the solution of a wide range of problems, namely:

- taking into account the world experience of introducing environmental regulation and taxation; this should contribute to the eco-friendly enterprises development, to the natural environment restoration, landscape and biological diversity conservation, the qualitative status of the components of nature, which will enable the population reproduction and its health state improvement;

- implementation of territorially differentiated structural restructuring of the economy with increasing role of ecological production, tertiary and quaternary sphere, consumer goods production, etc.;

- introduction of modern environmental, that is, resource-, energy-saving and low-waste technologies; 
- improvement of current resource-saving by attracting non-traditional types of resources into the economic circulation, integrated use of all raw materials, aimed at more complete development of all their useful components, reducing environmental pollution and increasing the output of one ton of raw materials;

- mitigation of the negative effects of economic environmental management through resource restoration, land reclamation, use of natural-technogenic resources (production wastes), combating adverse natural-technogenic processes (erosion, flooding, salinization, etc.);

- preservation of biological diversity, restoration of soil fertility through the introduction of integrated land reclamation and modern farming systems, the use of modern agricultural machinery, etc.;

- creation of an ecological framework of the territory, consistent with the territorial structure of the economy, expansion of the system of nature protection territories;

- development of extensive ecological infrastructure, placement of treatment facilities and environmental protection facilities, which would correspond to the maximum placement of environmentally harmful production facilities;

- provision of "green" investment, especially in regions of environmental disaster, for the implementation of all the above types of greening economy.

The mechanism of implementation of the strategy of sustainable (balanced) development of the country ought to be based on the principle of providing a multilevel system of actions and measures; each of the levels has its own specificity and solves its own complexes of tasks.

The action of a complex of objective and subjective external and internal factors has led to quite unfavourable initial positions of Ukraine regarding the possibility of transition to sustainable (balanced) development. Therefore, it must be stated that this process can be difficult and time-consuming. The modern complex realities constantly pose new challenges to the state and create new obstacles to sustainable (balanced) development.

In such circumstances, the duration of the transition and the stages of this process can only be determined in an indicative manner, and the duration of their implementation may not have clearly defined time limits. At the same time, the author considers that it is expedient and necessary to distinguish the following three stages of the country's transition to sustainable (balanced) development:

I - the compensation stage, access to pre-crisis indicators of economic and social development. 
It is known that at present the GDP of Ukraine is just over $70 \%$ of the indicators of the 1990s. The main indicator of entering the compensation stage has to be the pre-crisis GDP achievement. At the same time, the structure of GDP itself and its share of individual sectors of economy and types of economic activity ought to be completely different from those of the country more than twenty years ago. Innovative economic renewal and structural changes, such as those already undergone by advanced market economies, must be ensured. However, the negative experience of these countries and the possible consequences of excessive reduction of the real production sector in the national economy, the specifics and possibilities of the country economy development should be considered, taking into account the peculiarities of natural resource, human and other potentials of its development.

Given the overall situation and the current state of the globalized world economy development, it can be expected that the transition to this stage will take at least 10 years under the most optimistic scenario.

Stage II formation of starting positions - ensuring the initial competitive positions of the state in the world economy, ensuring the minimum values of the basic parameters of economic and social development, not lower than the world ones. In terms of environmental, economic and social indicators, it is necessary to achieve the corresponding values that will take place in the countries of Eastern Europe within the EU during this phase.

During the years of systemic crisis that Ukraine has experienced over the last two decades, the world economy has made a significant step forward in its development. New powerful countries have emerged on the world geo-economic map, and countries that were world leaders in the late 1990s, although slowing down somewhat, are still leaders in the world economy. During this period, Ukraine made a rapid decline.

In author's view, the main economic indicator of the country's entry into the starting position stage has to be the achievement of the world average production of gross national product (hereinafter - GNP) per person.

\section{Important economic indicators ought to be:}

- achievement of the world average output of production per one employed in the economy;

- achievement of the world average level of labour productivity in industry;

- achievement of a world average level of agricultural productivity.

\section{Important environmental and economic indicators have to be:}

- reaching the world average level of energy intensity of the economy;

- achievement of an average global water reservoir level; 
- achievement of the world average level of harmfulness of the economy for the atmosphere.

\section{Important social indicators ought to be:}

- achievement of average life expectancy at the level of the EU member states of Eastern Europe;

- achievement of child mortality rates at EU level in Eastern Europe;

- achievement of a share of food expenditure in household expenditure at EU level in Eastern Europe;

- meeting the share of spending on vacations and travel in household expenditure at EU level by Eastern European countries;

- achievement of a share of the costs of attending cultural institutions in household expenditure at the level of Eastern European countries that are members of the EU.

Considering the complexity and importance of the tasks to be solved in the second stage, it can be expected that its completion will also require at least ten years under the most optimistic scenario.

The third stage is the beginning of the transition to sustainable (balanced) development.

The third stage involves the achievement of the levels of basic economic, ecological, economic and social parameters that Ukraine will have in this period as a whole.

In author's view, the main economic indicator of a country's entry into the starting position has to be the achievement of GDP per capita GDP at EU average.

\section{Important economic indicators ought to be:}

- achievement of output per employee in the economy at the EU average;

- achievement of average level of industrial productivity at EU level;

- achievement of agricultural productivity at EU average.

\section{Important environmental and economic indicators have to be:}

- achievement of an average level of energy intensity of the economy at EU level;

- achievement of an economy-wide water reservoir at the EU average;

- achievement of an average level of harmfulness to the atmosphere at the EU average.

\section{Important social indicators ought to be:}

- achievement of average life expectancy at the EU average;

- achievement of child mortality rates at the EU average; 
- achievement of the share of household spending on household expenditure that equals to the average of the EU member states;

- meeting the share of spending on vacations and travel in household spending at the EU average;

- achieving the share of expenditure on cultural visits to household expenditures is equal to the average of EU countries.

Considering the complexity and importance of the tasks to be solved in the third stage, it can be expected that its completion will also require at least two decades under the optimistic development scenario.

\section{Conclusions}

Humanity entered the XXI century with a certain understanding of responsibility for the effects of man-made impact on nature. It is partly considered, at least at the government level, that the signed Rio-92 documents and subsequent fora provide for a fundamental change in the development, use and conservation of natural resources. In all countries of the world it is being discussed, and in most of them the new worldview paradigm of development - sustainable (balanced) development is being implemented.

In Ukraine there are an increasing number of supporters of understanding this process as a way of achieving a balance of economic, social, environmental and spiritual development based on certain basic equilibria. The main ones are:

- equilibrium between the integral natural-resource potential of the territory and the structures of production;

- equilibrium of ecological capacity of natural landscapes, taking into account their ability to self-regenerate natural properties and technogenic influence on them.

Currently, it can be observed that the needs of economic growth are still being met by the exploitation of natural resources and, consequently, by the loss of not only the resources themselves, but also the natural environmental properties of the components of nature, which leads to a decrease in the vitality of the planet.

\section{References}

1. Draft report of Ukraine to the UN Conference on Sustainable (Balanced) Development of Rio + 20. Lisovsky S., Marushevsky G., Pavlichenko P., Rudenko L., Tymochko T. - K .: Center of environmental education and information. 2012.-60 p. 
2. Status of implementation of the provisions of the Agenda for the 21st Century in Ukraine (2002 - 2012) / Ed. by Rudenko L. - K.: Akademperiodika, 2014.-359 p.

3. Association Agreement between Ukraine and the European Union, official text. [Electronic resource]. - Access mode: http://www.kmu.gov.ua/kmu/control/en/publish/ article?art_id=246581344\&

4. Rio Declaration on Environment and Development [Electronic resource] - Access mode: http://zakon2.rada.gov.ua/laws/show/995_455

5. Conceptual Basics of Sustainable Territorial Development Programming [Electronic resource] - Access mode: https://mindjournal.wseh.pl/sites/default/files/article/03-17/ konceptualnye_osnovy_programmirovaniya_ustoychivogo_territorialnogo_razvitiya.pdf 